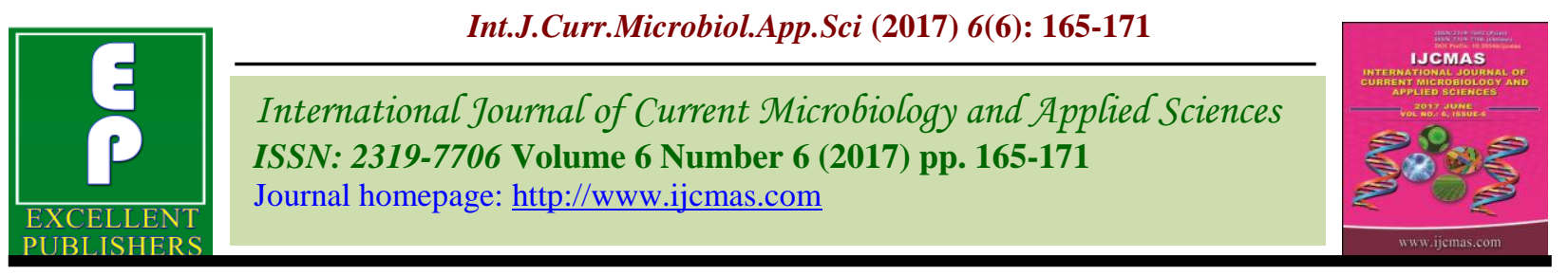

Original Research Article

https://doi.org/10.20546/ijcmas.2017.606.020

\title{
Evaluation of Spinosad against Malathion and Deltamethrin Resistant Population of Lesser Grain Borer, Rhyzopertha dominica in Andhra Pradesh, India
}

\author{
S. Ramesh Babu*, D.V. Sai Ram Kumar, C.H. Naga Satya Sri and T. Madhumathi \\ Department of Entomology, Agricultural College, Bapatla, Acharya N.G. Ranga Agricultural \\ University, Guntur - 522 101, Andhra Pradesh, India \\ *Corresponding author
}

\section{A B S T R A C T}

\begin{tabular}{|l|}
\hline Key w or d s \\
R. dominica, \\
Malathion, \\
Deltamethrin, \\
Spinosad, \\
Resistance. \\
\hline Article Info \\
\hline Accepted: \\
04 May 2017 \\
Available Online: \\
10 Iune 2017 \\
\hline
\end{tabular}

A laboratory experiment was carried out in the Department of Entomology Agricultural College, Bapatla to know the resistance levels of malathion and deltamethrin against lesser grain borer, Rhyzopertha dominica and management with new insecticide molecule spinosad. The degree of resistant acquired by resistant population of $R$. dominica 3.80 folds resistant at LC50 and 2.61 folds resistant at LC99.9 level to malathion in comparison with laboratory susceptible strain at 72 HAT $($ LC50 $=0.0057 \%$ and LC99.9 = 1.3337\%). 1.60 folds resistant at LC50 (0.0345) and 3.83 folds resistant at LC99.9 (3.4338) level to deltamethrin, respectively in comparison with laboratory susceptible strain at 72 HAT (LC50 = $0.0215 \%$ and LC99.9 $=0.8965 \%$ ). Insecticide tested for the management of malathion and deltamethrin resistant population of $R$. dominica, Spinosad was found to be the best at LC99.9 level with the relative toxicity (1.55 and 2.46 times) than malathion and deltamethrin respectively.

\section{Introduction}

In India, annual storage losses were estimated as 13.98 million tonnes of food grains worth of Rs. 6845 crores of every year. Out of this, food grain losses due to insects alone account for nearly Rs.1275 crores (Mohan and Kavitharaghavan, 2008). In India, approximately 10 per cent of food grains were lost during storage and half of which is due to insect pests (Narang, 2002). During storage, various biotic and abiotic factors are responsible in deterioration of physical and chemical quality of the food grains and amongst the biotic factors, insect pests cause the major damage.
Among the several storage insect pests, the lesser grain borer, Rhyzopertha dominica (Fabricius) (Bostrichidae: Coleoptera), is a primary pest of stored food grains such as paddy, wheat, maize and sorghum but can also infest various other commodities including pulses and dried cassava root. The beetle has been reported to be highly polyphagous and cosmopolitan in tropical and subtropical regions of the world, but it has also been found in some warm and temperate regions (Potter, 1935; Haines, 1991). The weight loss in wheat by the feeding of grub and adult stages of $R$. dominica was 5 and 149 $\mathrm{mg} \mathrm{kg}^{-1}$, respectively (Hagstrum and 
Subramanyam, 2006). Development of insecticide resistance in insect pests of crops has become a major constraint both in crop protection and crop production. The instance of insecticide resistance was first noted in Sanjose scale, Quadraspidiotus periniciosus (Comstock) (Melander, 1914). Due to the resistance by insect pests and negative effects of synthetic pesticides to the environment, it is necessary to use novel and suitable compounds in insect pest's management. Spinosad is a bio-insecticide that is derived from fermentation of a bacterium Saccharopolyspora spinosa Mertz and Yao. In the present study, the toxicity of Tracer® as a spinosad based insecticide evaluated against malathion and deltamethrin resistant population of $R$. dominica.

\section{Materials and Methods}

\section{Rearing of the test insect}

The field population of the test insect, $R$. dominica, collected from the Rice Research Unit (Bapatla) were maintained on wheat grains in laboratory during 2015. Initially the wheat grains were disinfested by fumigating with aluminium phosphide tablets@one per $30 \mathrm{~kg}$ grains for seven days to ensure that they were free from insects and mites. Then the grains were well aerated to remove phosphine residues. About $250 \mathrm{~g}$ of wheat grains were taken in a plastic jar measuring $45 \times 15 \mathrm{~cm}$ and about 20 adults were released into it for oviposition. Adults were removed after 20 days and released into another jar containing wheat grains, thus a succession of the insects was maintained for utilizing the eggs laid staggeredly to ensure constant supply of test insects of known age. The newly emerged adults were transferred into new containers with fresh wheat grains and used for the multiplication of culture and also for conducting the experiments. The pest population was maintained at an optimum temperature of $32+1^{0} \mathrm{C}$ and 75 per cent relative humidity throughout the period of investigation (Andrewartha, 1961).

\section{Test insecticides}

The test insecticides selected for studying the degree of resistance acquired by $R$. dominica were malathion and deltamethrin which are commonly used in the grain store houses for the control of stored grain insect pests and for management selected insecticide is Spinosad is a bio-insecticide that is derived from fermentation of a bacterium Saccharopolyspora spinosa.

\section{Test insect population}

The adult beetles of $R$. dominica (seven days old) of F1 generation, reared in the laboratory from the initial culture obtained from the Rice Research Unit (RRU) - Bapatla, Andhra Pradesh were subjected to bioassay. The laboratory culture of $R$. dominica which is being maintained in the Department of PostHarvest Technology Centre (PHTC), Agricultural college, Bapatla, without any insecticidal exposure and were sustained as susceptible strain.

\section{Bioassay with jute cloth disc impregnation method}

The adult beetles of $R$. dominica of one week old were subjected to the bioassay with the test insecticides by following jute cloth disc impregnation method (Najitha et al., 2013). Stock solution of one per cent concentration of respective test insecticides was prepared by weighing the required quantities of insecticides, by using acetone as solvent. The graded concentrations of the test insecticides were prepared with acetone as solvent by following serial dilution technique. The quantity of insecticidal solution required to impregnate the jute cloth of nine centimeters 
diameter was determined. After impregnation, the jute cloth discs are air dried. One day old beetles were collected from the culture and kept under starvation for two hours. The starved beetles are transferred to the petriplates containing insecticide impregnated jute cloth disc @ 20 beetles/petriplate in three replications for each test insecticide. The insects were confined to the treated surface for 24 hours, 48 hours and 72 hours. Simultaneously, a control was also maintained with jute cloth disc impregnated in acetone only.

\section{Data collection}

Mortality was recorded at 24, 48 and 72 hours after treatment (HAT). A preliminary experiment was conducted with wide range of concentrations followed by a narrow range to get mortality in the range of $5-90 \%$. There was no occasion of the use of Abbott's formula since mortality was not recorded in control, because of the use of almost same age beetles and the experiment conducted under controlled ambient conditions of $32^{\circ} \mathrm{C}$ temperature and 75 per cent relative humidity. Moreover, a separate set of new petriplates were utilized for control avoiding the use of petriplates that were used for insecticidal treatments. In order to know the immediate toxicity of the chemical, the mortalities were recorded at $24 \mathrm{HAT}$ and subsequently at 48 HAT. Mortality at 72 HAT was also recorded to know the mortality end point.

\section{Assessment of the degree of resistance}

The mortality data of adult beetles against all the test insecticides were subjected to probit analysis (Finney, 1971) using SPSS (Statistical Package for Social Sciences) to calculate (Median Lethal Concentration) LC50, LC99.9, heterogeneity ( $\chi 2)$, intercept: (a), slope of the regression line (b), regression equation and fiducial limits. The degree of resistance acquired by $R$. dominica were calculated for the data at 72 HAT by dividing the higher LC50 / LC99.9 value of resistant strain with the LC50 / LC99.9 value of susceptible strain and thus the relative degree of resistance was assessed.

\section{Results and Discussion}

\section{Resistance of malathion and deltamethrin to $R$. dominica}

The resistant population of $R$. dominica recorded LC50 and LC99.9 values as 0.0578 and 8.1402 per cent, respectively to malathion at 24 HAT. The corresponding values slightly decreased with increased mortality at 48 HAT $(0.0387 \%$ and $6.9915 \%)$ and at 72 HAT $(0.0217 \%$ and $3.4883 \%)$. The slope (b) values of $\log$ concentration probit (lcp) lines of malathion were $1.082,1.030$ and 1.054 at 24, 48 and 72 HAT, respectively. The chisquare test revealed the homogeneity of the test population $(\mathrm{P}<0.05) \quad$ (Table 1). The degree of resistant acquired by resistant population of $R$. dominica 3.80 folds resistant at LC50 and 2.61 folds resistant at LC99.9 level to malathion in comparison with laboratory susceptible strain at 72 HAT $($ LC50 $=0.0057 \%$ and LC99.9 $=1.3337 \%)$ (Table 3).

The data revealed that LC50 and LC99.9 values of deltamethrin with resistant strain of $R$. dominica at 24 HAT were 0.0752 and 6.3903 per cent, respectively. At 48 and 72 HAT there was a slight increase in the mortality with consequent decrease in the LC50 (0.0533 and $0.0345 \%)$ and LC99.9 $(5.2900 \%$ and $3.4338 \%)$ values, respectively. The slope (b) values of log concentration probit (lcp) lines were 1.205, 1.165 and 1.164 at 24,48 and 72 HAT, respectively. The chisquare test revealed the homogeneity of the test population $(\mathrm{P}<0.05)$ (Table 2$)$. 
Table.1 Relative toxicity of malathion to resistant and susceptible population of lesser grain borer, Rhyzopertha dominica from Andhra Pradesh

\begin{tabular}{|c|c|c|c|c|c|}
\hline $\begin{array}{c}\text { Hours after } \\
\text { treatment }\end{array}$ & $\mathrm{LC}_{50} \%(95 \% \mathrm{FL})$ & $\mathrm{LC}_{99.9} \%(95 \% \mathrm{FL})$ & Slope b $( \pm \mathrm{SE})$ & $\begin{array}{c}\text { Heteroge } \\
\text { neity } \\
(\chi 2)\end{array}$ & $\begin{array}{c}\text { Regression } \\
\text { Equation } \\
(\mathbf{Y}=\mathbf{a}+\mathbf{b x})\end{array}$ \\
\hline \multicolumn{6}{|c|}{ Resistant population } \\
\hline 24 & $0.0578(0.0432-0.0824)$ & $8.1402(2.8953-40.1016)$ & $1.082( \pm 0.120)$ & 3.72 & $Y=2.33+1.67 x$ \\
\hline 48 & $0.0387(0.0290-0.0536)$ & $6.9915(2.4898-34.3798)$ & $1.030( \pm 0.115)$ & 3.19 & $\mathrm{Y}=1.39+2.11 \mathrm{x}$ \\
\hline 72 & $0.0217(0.0162-0.0288)$ & $3.4883(1.4029-13.8462)$ & $1.054( \pm 0.113)$ & 2.40 & $\mathrm{Y}=3.11+1.39 \mathrm{x}$ \\
\hline \multicolumn{6}{|c|}{ Susceptible population } \\
\hline 24 & $0.0172(0.0128-0.0227)$ & $2.5359(1.0736-9.2291)$ & $1.072( \pm 0.114)$ & 2.35 & $Y=2.61+1 . .39 x$ \\
\hline 48 & $0.0116(0.0083-0.0155)$ & $1.9305(0.8225-7.0633)$ & $1.047( \pm 0.114)$ & 1.91 & $Y=2.61+1.39 x$ \\
\hline 72 & $0.0057(0.0035-0.0082)$ & $1.3337(0.5499-5.4417)$ & $0.982( \pm 0.118)$ & 2.44 & $\mathrm{Y}=2.61+1.39 \mathrm{x}$ \\
\hline
\end{tabular}

Table.2 Relative toxicity of deltamethrin to resistant and susceptible population of lesser grain borer, Rhyzopertha dominica from Andhra Pradesh

\begin{tabular}{|c|c|c|c|c|c|}
\hline $\begin{array}{c}\text { Hours after } \\
\text { treatment }\end{array}$ & $\mathbf{L C}_{50} \%(95 \% \mathrm{FL})$ & $\mathrm{LC}_{99.9} \%(95 \% \mathrm{FL})$ & Slope b $( \pm$ SE $)$ & $\begin{array}{c}\text { Heterog } \\
\text { eneity } \\
(\chi 2) \\
\end{array}$ & $\begin{array}{c}\text { Regression } \\
\text { Equation } \\
(\mathbf{Y}=\mathbf{a}+\mathbf{b x}) \\
\end{array}$ \\
\hline \multicolumn{6}{|c|}{ Resistant population } \\
\hline 24 & $0.0752(0.0581-0.1059)$ & $6.3903(2.2113-38.5913)$ & $1.205( \pm 0.161)$ & 3.65 & $Y=2.0+1.67 x$ \\
\hline 48 & $0.0533(0.0415-0.0713)$ & $5.2900(1.9117-28.8660)$ & $1.165( \pm 0.151)$ & 4.47 & $Y=2.5+1.67 x$ \\
\hline 72 & $0.0345(0.0265-0.0444)$ & $3.4338(1.3685-15.3492)$ & $1.164( \pm 0.145)$ & 5.05 & $Y=3.0+1.67 x$ \\
\hline \multicolumn{6}{|c|}{ Susceptible population } \\
\hline 24 & $0.0576(0.0461-0.0744)$ & $3.0305(1.3149-11.4872)$ & $1.351( \pm 0.161)$ & 6.36 & $Y=2.5+1.67 x$ \\
\hline 48 & $0.0294(0.0237-0.0359)$ & $1.0142(0.5667-2.3903)$ & $1.513( \pm 0.153)$ & 3.94 & $\mathrm{Y}=3.3+2.00 \mathrm{x}$ \\
\hline 72 & $0.0215(0.0167-0.0267)$ & $0.8965(0.4970-2.1473)$ & $1.435( \pm 0.148)$ & 5.41 & $\mathrm{Y}=2.2+1.33 \mathrm{x}$ \\
\hline
\end{tabular}


Table.3 Degree of resistance acquired by the adults of Rhyzopertha dominica to Malathion and Deltamethrin

\begin{tabular}{|c|c|c|c|c|}
\hline \multirow{3}{*}{ Name of the strain } & \multirow{3}{*}{$\mathbf{L C}_{50}(\%)$} & \multirow{3}{*}{$\mathrm{LC}_{99.9}(\%)$} & \multicolumn{2}{|c|}{ Resistance Factor } \\
\hline & & & \multicolumn{2}{|c|}{ In comparison with Laboratory Susceptible strain } \\
\hline & & & $\mathbf{L C}_{50}$ & $\mathbf{L C}_{99.9}$ \\
\hline \multicolumn{5}{|l|}{ Malathion (50 \% EC) } \\
\hline Resistant population & 0.0217 & 3.4883 & 3.80 & 2.61 \\
\hline Susceptible strain & 0.0057 & 1.3337 & - & - \\
\hline \multicolumn{5}{|c|}{ Deltamethrin (2.8 \% EC) } \\
\hline Resistant population & 0.0345 & 3.4338 & 1.60 & 3.83 \\
\hline Susceptible population & 0.0215 & 0.8965 & - & - \\
\hline
\end{tabular}

Table.4 Toxicity of newer insecticide Spinosad against resistant population of lesser grain borer, Rhyzopertha dominica

\begin{tabular}{|c|c|c|c|c|c|}
\hline $\begin{array}{c}\text { Hours after } \\
\text { treatment }\end{array}$ & $\mathrm{LC}_{50} \%(95 \% \mathrm{FL})$ & $\mathrm{LC}_{99.9} \%(95 \% \mathrm{FL})$ & Slope b $( \pm$ SE $)$ & $\begin{array}{c}\text { Heterogene } \\
\text { ity } \\
(\chi 2)\end{array}$ & $\begin{array}{c}\text { Regression } \\
\text { Equation } \\
(\mathbf{Y}=\mathbf{a}+\mathbf{b x}) \\
\end{array}$ \\
\hline \multicolumn{6}{|c|}{ Spinosad (45\% EC) } \\
\hline 24 & $0.0408(0.0306-0.0550)$ & $9.2036(3.6004-36.2502)$ & $0.988( \pm 0.097)$ & 2.58 & $Y=1.6+1.20 x$ \\
\hline 48 & $0.0263(0.0195-0.0352)$ & $6.3751(2.6270-22.9111)$ & $0.975( \pm 0.097)$ & 5.08 & $Y=2.1+1.20 x$ \\
\hline 72 & $0.0140(0.0099-0.0190)$ & $3.7266(1.6228-12.2460)$ & $0.959( \pm 0.095)$ & 8.07 & $Y=2.6+1.20 x$ \\
\hline
\end{tabular}


Table.5 Relative toxicity of newer insecticide Spinosad in comparison with Malathion and Deltamethrin against resistant population of lesser grain borer, Rhyzopertha dominica for its management at 72 HAT

\begin{tabular}{|c|c|c|c|c|}
\hline \multirow{3}{*}{$\begin{array}{l}\text { Hours after } \\
\text { treatment }\end{array}$} & \multicolumn{4}{|c|}{ Relative toxicity of Spinosad (45 \% EC) } \\
\hline & \multicolumn{2}{|c|}{ Over Malathion } & \multicolumn{2}{|c|}{ Over Deltamethrin } \\
\hline & $\mathbf{L C}_{50}$ & $\mathrm{LC}_{99.9}$ & $\mathbf{L C}_{\mathbf{5 0}}$ & $\mathrm{LC}_{99.9}$ \\
\hline 24 & 1.41 & 0.88 & 1.84 & 0.69 \\
\hline 48 & 1.47 & 1.09 & 2.02 & 0.82 \\
\hline 72 & 1.55 & 0.93 & 2.46 & 0.92 \\
\hline
\end{tabular}

The Bapatla strain showed 1.60 folds resistance at LC50 and 3.83 folds resistance at LC99.9 level to deltamethrin in comparison with Laboratory susceptible strain (LC50 = $0.0215 \%$ and LC99.9 $=0.8965 \%$ ) at 72 HAT (Table 3).

Several studies in the past have also shown that many op insecticides including malathion resulted in the development of resistance in many insect species including lesser grain borer (badmin, 1990; rossiter et al., 2001). Sublethal doses of malathion greatly suppressed acp (acid phosphatase) activity in resistant beetles, which might be due to inhibition of this enzyme under insecticidal toxicity and impairing of the lysosomal activity to hydrolyze the macromolecules and in turn limiting the ability of the resistant beetles to use energy rich compounds to obtain energy. The present results were on par with those of Kumar et al., (2010), who reported that a strain of $T$. granarium has developed resistance which is ranged from 1.55 to 3.65 folds in six successive generations at 80 per cent selection pressure.

\section{Efficacy of spinosad against malathion and deltamethrin resistant population}

It was estimated from the data (Table 4) that the LC50 values of spinosad to the adults of resistant strain of $R$. dominica were 0.0408 , 0.0263 and 0.0140 per cent while the respective LC99.9 values were 9.2036, 6.3751 and 3.7266 at 24, 48 and 72 HAT, respectively. The slope (b) values of $\log$ concentration probit (lcp) lines for spinosad were $0.988,0.975$ and 0.959 at 24,48 and 72 HAT, respectively. The chi-square test revealed that the population used in the study was homogenous $(\mathrm{P}<0.05)$.

Spinosad at LC50 level was 1.41, 1.47 and 1.55 times more toxic than malathion at 24 , 48 and 72 HAT, respectively. The corresponding value was 1.84, 2.02 and 2.46 times more toxic than deltamethrin at 24,48 and 72 HAT. At LC99.9 level less relative toxicity in comparison with malathion and deltamethrin (Table 5).

The LC50 and LC99, 9 values insecticide was spinosad (0.0140\% and $3.7266 \%)$ against $R$. dominica. Similarly, Mutambuki et al., (2002) also reported complete control of $R$. dominica adults when exposed to a dust formulation of spinosad (0.125 a.i. D) on corn treated with 0.7 to 1.4 mg.kg-1 seed. Similarly, Toews and Subramanyam (2003) recorded cent per cent mortality of $R$. dominica with spinosad @ 0.0016 and $0.016 \mathrm{mg} . \mathrm{cm}^{-2}$ on glass surface. Similarly, a residual deposit of spinosad @ 0.05 and $0.1 \mathrm{mg} . \mathrm{cm}^{-2}$ of surfaces viz., concrete surface, galvanized floor, un waxed floor tile and waxed floor tile gave cent per cent mortality of adults of eight stored product beetles viz., $R$. dominica, $T$. 
castaneum, T. confusum, T. variabile, $S$. oryzae $O$. surinamensis, $C$. ferrugineus (Toews et al., 2003).

\section{Acknowledgments}

The authors are highly grateful to the managers of CWC godowns of Bapatla for the help rendered during collection of test strains from Bapatla.

\section{References}

Andrewartha, H.G. 1961. Introduction to the study of animal populations. Chapman and Hall Ltd. 261-262.

Badmin, J.S. 1990. IRAC survey of resistance of stored grain pests: Results and Progress. Proceedings of the Fifth International Working Conference on Stored Product Protection. Bordeaux, France. 973-982

Finney, D.J. 1971. Probit analysis. Cambridge University Press, London. 109

Hagstrum, D.W., and Subramanyam, B. 2006. Fundamentals of Stored - Product Entomology. AACC international press, USA. 15.

Haines, C.P. 1991. Insects and arachinids of tropical stored products: their biology and identification (A training manual). Natural Resources Institute. Chatham, UK. 246.

Kumar, M.K., Srivastava, C., and Garg, A.K. 2010. In vitro selection of deltamethrin resistant strain of Trogoderma granarium and its susceptibility to insecticides. Annals Plant Protection Sciences. 18(1): 26-30.

Melander, A.L. 1914. Can insects become resistant to sprays? Journal of Economic Entomology. 7: 167.

Mohan, S., and Kavitharaghavan, Z. 2008. Studies on the popularization of TNAU stored product insect management kit technology. Green Farming. 46: 53.

Mutambuki, K.C.M., Ngatia, J., Mbugua, N., and Likhayo, P. 2002. Evaluation of the efficacy of spinosad dust against major stored insect pests. Proceedings of 8th International Working Conference on Stored Product Protection, July 22-26, Newyork, UK. Wallingford: CAB international. 888-891.

Najitha U., Madhumathi, T., and Krishnayya, P.V. 2013. Efficacy of insecticides against Caryedon serratus (Olivier) on jute cloth disc Surface. Pesticide Research Journal. 25(1): 63-65.

Narang, D.D. 2002. Banish the Pests Feeding on our Grain. In the Tribune September 23, Chandigarh India.

Potter, C. 1935. The biology and distribution of Rhyzopertha dominica (Fab.). Transactions of the Royal Entomological Society. 83: 449-482.

Rossiter, L.C., Gunning, R.V., and Rose, H.A. 2001. The use of Polyacrylamide Gel Electrophoresis for the investigation and detection of fenitrothion and chlorpyrifosmethyl resistance in Oryzaephilus surinamensis (L.) (Coleoptera, Silvanidae). Pesticide Biochemistry and Physiology. 69: 27-34.

Toews, M.D., and Subramanyam, B. 2003. Contribution of contact toxicity and wheat contribution to mortality of stored product insects exposed to spinosad. Pest Management Science. 59: 538-544.

Toews, M.D., Subramanyam, B., and Rowan, J.M. 2003. Knockdown and mortality of adults of eight species of stored - product beetles exposed to four surfaces treated with spinosad. Journal of Economic Entomology. 96(6): 1967-1973.

\section{How to cite this article:}

Ramesh Babu, S., D.V. Sai Ram Kumar, C.H. Naga Satya Sri and Madhumathi, T. 2017. Evaluation of Spinosad against Malathion and Deltamethrin Resistant Population of Lesser Grain Borer, Rhyzopertha dominica in Andhra Pradesh. Int.J.Curr.Microbiol.App.Sci. 6(6): 165-171. doi: https://doi.org/10.20546/ijcmas.2017.606.020 